\title{
The Role of World Food Programme in Improving the Conditions of the Syrian Refugees in Jordan
}

\author{
Hazem Samed Abed Abu Orabi Al Adwan
}

\begin{abstract}
The study aimed to search in the role of world food programme in improving the conditions of the Syrian refugees in Jordan. The study followed the descriptive analytical approach, and the sample consisted of (220) Syrian refugees inside and outside the Zaatari camp in Jordan, and the study tool, which is represented in the questionnaire, was developed, and the study found that the level of improvement in the living conditions of Syrian refugees in Jordan as a result of the World Food Program came with a medium degree, as it reached The study indicated that the level of improvement of the health conditions of Syrian refugees in Jordan as a result of the World Food Program came at a moderate degree, and the study found that there were no statistically significant differences in the estimates of Syrian refugees in the extent of the contribution of the World Food Program to improving conditions for refugees in Jordan according to the gender variable, and the presence of differences according to The location variable came in favor of the refugees inside the camp, and the study recommended increasing the allocations provided by the governments of the world countries to support the World Food Program to better provide its services.
\end{abstract}

Keywords: World Food Programme, Syrian Refugees

DOI: $10.7176 / \mathrm{JEP} / 11-18-16$

Publication date:June 30th 2020

\section{Introduction:}

Refugees around the world try to integrate into the societies in which they live, and refugee organizations work to reduce the psychological and social damage that refugees may be exposed to and work to empower them with the aim of improving their social conditions by helping them in productive projects and ensuring basic nutrition for them and their children.

Over the past years, the world has faced one of the largest exoduses in recent history in the Syrian conflict. One direct implication of this conflict is large-scale population displacement. Indeed, approximately 3 million Syrians have fled their country in search of a safe haven along the borders with the country's immediate neighbors, namely, Lebanon, Jordan, Turkey and Iraq. Such a humanitarian crisis has prompted governments in these countries to receive and host refugees of different age groups, genders, religious affiliations and income levels (Fakih \& Ibrahim, 2016).

Jordan has received a large share of Syrian refugees, currently totaling to the alarming number of $1.2 \mathrm{mln}$ people and based on the Jordanian government's estimate, the direct cost of Syrian refugees for the government since the beginning of the crisis in 2011 to 2016 was about $\$ 4.2$ billion so Jordanians have revealed concerns about their open border policy; they have also been cautioned regarding the competition over scarce resources and limited public budgeting (Alshoubaki \& Harris (2018).

WFP assistance to Syrian refugees in Jordan was essential to ensure food security levels remained stable in 2018. The introduction of unrestricted cash allowed refugees to meet their needs according to their priorities and contributed to the reduction of negative coping strategies such as selling food commodities, with positive longerterm effects on food security. WFP continued to support vulnerable Jordanians and plans to provide technical assistance to the National Aid Fund in 2019 to expand the social protection coverage of its cash programme for vulnerable Jordanians, building on WFP's expertise in the field of digitization of cash delivery systems (WFP, 2019).

While Jordan is stable, it suffers from a range of existing and emerging challenges. Syrian refugees pose several challenges and stability risks to the government of Jordan (GoJ), but it does not appear that any of these constitute an existential threat to the overall stability of the Hashemite Kingdom. There are three key areas of concern, each of which is addressed in this report: economic, social, and physical security. The risk across each of these categories is manageable, and, if present integration trends continue, the refugees might have a positive effect on both the Jordanian economy and society (Connable, 2015).

While humanitarian assistance is acting as a buffer, food security amongst Syrian refugees in Jordan remains precarious. Less than one in four Syrian refugees ( 23 percent) are food secure, compared to 28 percent in 2016. Short-term coping mechanisms used to deal with a lack of food such as reducing the number of meals and restricting adult consumption increased. While most Syrian refugees have at least one family member working and the number of issued work permits has increased in recent years, access to dignified and reliable work remains an issue for this affected population (WFP, 2019).

Its noted that in many host communities, the economic impact of Syrian refugees and humanitarian 
assistance has been the subject of significant debate. The Syrian crisis has clearly had an overall negative impact on many neighboring countries' economies by affecting trade flows, GDP and growth, and could threaten regional stability. However, as over $90 \%$ of refugees live outside camps, they have become important customers for local goods and services, paid for with savings, labour income, remittances and humanitarian assistance. Local businesses also benefit from humanitarian assistance programmers as they get contracted as suppliers for non-governmental organizations (NGOs) and humanitarian agencies (Schillings, 2018).

The Syrian refugees in Jordan can be divided into two parts: one section lives inside the camps and the other section lives outside it, as is the case in other countries, and it has become clear that $20 \%$ of the Syrians live inside the camps, while $80 \%$ live outside, and the Jordanian northern border region has witnessed an exceptional circumstance since the beginning The Syrian crisis has resulted in the entry of hundreds of thousands of Syrian refugees. In this context, the Directorate of Refugee Affairs in Jordan has worked to define strategic plans and joint work policies with the participation of relevant ministries and relevant state and local organizations, and to develop a national plan for resettlement and access to respond to all refugee issues that include providing security, voluntary return and residency and humanitarian and relief services, and working with The rest of the ministries, donor countries, and international NGOs to implement the host community rehabilitation program, develop infrastructure for refugee housing, and develop the services of the areas in which they live through community projects, where they worked to find institutional building capable of protecting 17 refugee people by training the security services, ministries, and organizations On working with this class (AlHamoud, 2015).

The Zaatari camp is located in the city of Mafraq and was established in 2012, and security is provided inside the camp with the assistance of the Jordanian Security Directorate, and the Commission provides financial support, food distribution and health services provision within the camp

Here, we are trying to shed light on the extent of the contribution of the World Food Program to providing food security for the Syrian refugees in Jordan, which contributes to improving their living conditions and promoting economic development in the camps and their places in society.

\section{Study Problem:}

The nutritional problem is considered one of the main problems facing the third world countries, and this problem increases with the presence of refugees due to the importance of providing them with basic foodstuffs. In Jordan, the issue of the Syrian refugees is of concern to the Jordanian government and international organizations related to refugees.

Civil unrest in the Syrian Arab Republic in 2011 led to a major humanitarian crisis in the region, which was declared a United Nations Level 3 emergency in January 2013. WFP's responses to the crisis are among the largest and most complex operations it has ever undertaken. From 2011 to 2014, the number of refugees increased to 3 million and at least 4.5 million displaced people became food-insecure in Syria. WFP's responses were implemented in challenging circumstances as needs inside and outside the country quickly increased, and as WFP strove to manage impartial and neutral relationships with national governments, donors, other humanitarian actors and affected populations (Drummond, et al, 2014).

Two major refugee assistance programs - the UNHCR cash assistance and food coupons program - are highly effective in reducing poverty. At the level of each program separately, it could lead to a reduction in the poverty rate among refugees.

Therefore this study problem is: What is the role of world food programme in improving the conditions of the Syrian refugees in Jordan?

\section{Study Objectives and Questions:}

This study aimed to explore the role of world food programme in improving the conditions of the Syrian refugees in Jordan. Therefore, this study aimed to answers to those questions:

1. Is world food programme improving the conditions of the Syrian refugees in Jordan from refugees point view?

2. Is there any statistically significant difference in improving the conditions of the Syrian refugees due to world food programme which can be attributed to (gender, location)?

\section{Study Importance:}

This study is important because it explores the extent of the World Food Program's contribution to improving the living conditions of Syrian refugees in Jordan, and the importance of the study increases as it studies the phenomenon from the point of view of the refugees themselves, and that the sample of the study included refugees from inside and outside the camp, and on the whole in the importance of providing food Refugees are a priority for governments and international organizations that work with Syrian refugees in Jordan and other countries. 


\section{Definition of Terms:}

World Food Programme (WFP): is the humanitarian organization saving lives and changing lives, delivering food assistance in emergencies and working with communities to improve nutrition and build resilience. As the international community has committed to end hunger, achieve food security and improved nutrition by 2030 , one in nine people worldwide still do not have enough to eat (WFP, 2020).

Syrian refugees: are the citizens and permanent residents of Syria, who have fled their country over the course of the Syrian Civil War.

Asylum can be defined as the legal protection granted by a state in the face of the actions of another country and that it takes place within specific places, either the territory of the state or another place of its own abroad, and this protection is granted only to a foreigner who has characteristics that distinguish him from the rest of the foreigners so that a refugee description applies to him According to international law (Burhan, 1982, 44).

\section{The Limitation of the Study:}

\section{The study is determined as follows:}

Spatial: This study includes Syrian refugees inside the Zaatari camp and outside the camp in the Jordanian city of Mafraq.

Time: The study was conducted during the first quarter of 2020.

Humanity: This study is limited to Syrian refugees.

\section{Literature Review:}

WFP (2019) report conclude that focus on innovation and digitization was strengthened to enhance accountability, cost-efficiency, effectiveness, and inform programmatic changes. WFP's Building Blocks project which started in 2017 was expanded to camps using block chain technology to make cash transfers to Syrian refugees more efficient, transparent and secure, as digitization speeds up the processing and settlement of transactions and reduces transaction costs while lowering the chances of fraud or data mismanagement. To expand block chain partnerships in 2019, WFP and UN Women will collaborate to assist Syrian women refugees in camps, who will be able to request cash back at WFP-contracted supermarkets or make their purchases directly, while UN Women and WFP will validate each other's transaction through the common platform.

Schillings (2018) study the effects of humanitarian assistance in response to the Syria crisis finds significant positive impacts for regional economic growth and job creation. The study reported that with currently 5.6 million registered Syrian refugees being hosted by neighboring countries and over six million internally displaced within Syria, creating economic opportunities has become a central component of the resilience approach in response to the crisis. Acknowledging the destructive impact of the conflict on livelihoods and economic resources, the international community committed to creating 1.1 million jobs for refugees and host communities by the end of 2018. This ambitious goal, announced at the London Conference for Supporting Syria and the Region in February 2016, is complemented by commitments from the affected national governments neighboring Syria (to open up their labour markets and improve their regulatory environment), the international community (to strengthen job creation through access to concessional financing and external markets) and the private sector (to foster economic growth by providing new investments).

Fakih \& Ibrahim (2016) analyzes time-sensitive data on a humanitarian crisis in the Middle East. It aims to assess the impact of the steep influx of Syrian refugees into Jordan on the country's labor market since the onset of the conflict in Syria (March 2011).. Jordan and Lebanon are hosting the majority of them. This paper utilizes data regarding unemployment rates, employment rates, labor force participation, the number of refugees, and economic activity at the level of governorates. The Vector Autoregressive (VAR) methodology is used to examine time series data from the most affected governorates in Jordan. The empirical results of Granger causality tests and impulse response functions show that there is no relationship between the influx of Syrian refugees and the Jordanian labor market. Our results are verified through a set of robustness checks.

Connable (2015) investigate how the Syrian refugee crisis can improve Jordan's outlook. The study reported that government of Jordan has a good understanding of the challenges associated with caring for and providing employment to the displaced Syrians. Also Syrians will continue to absorb many of the low-paying, low-skill jobs within Jordan's informal economy. Current laws prevent most Syrians from affecting the formal economy. Lack of employment, underemployment, and poverty will likely continue to leave large portions of the Syrian refugee population somewhat vulnerable to criminal and extremist recruitment. Syrian refugees are likely to benefit the Jordanian economy in several ways. Perceptions of the Syrian refugees' impact on employment might worsen as Syrians become more adept at finding work.

Husain et el (2014) investigate the direct and indirect impact of the food voucher programme in Jordan. this study finds that for every dollar spent by a voucher beneficiary, participating stores spend 85 cents on wholesale food purchases, six cents on operational costs, three cents on wages, two cents on taxes and one cent on capital expenditure. The programme has also led to some US\$2.5 million investment in physical infrastructure by the 
participating retailers; created over 350 jobs in the food retail sector; and generated about US\$6 million in additional tax receipts for the Jordanian government. In terms of indirect effects, this study finds a predictive multiplier ranging from 1.019 to 1.234 . In other words, WFP's plan to distribute US\$250 million in vouchers during 2014 would lead to some US\$255-US\$308 million of indirect benefits for the Jordanian economy. These indirect benefits are mostly concentrated in the agriculture, the manufacturing and the food products sectors. Had WFP opted for in-kind assistance, a larger share of these multipliers would have accrued outside of Jordan.

Drummond at el (2014) conduct evaluation of WFP's regional response to the Syrian crisis. The evaluation concluded that WFP responded to a fast-evolving, complex crisis and helped to improve and stabilize food security among the people it reached. The response was scaled up quickly, assisting 4.25 million people in Syria and 2 million refugees across the region in 2014, and accounting for 26 percent (in US dollar terms) of WFP's global operations. WFP funding requirements comprised 23 percent of the Syria Regional Refugee Response Plan and 42 percent of the Syria Humanitarian Assistance Response Plan in 2014, WFP's logistics and procurement operations for the regional response were particularly commended. With markets operating normally in surrounding countries, WFP quickly scaled up its electronic voucher programmes to levels unprecedented in a humanitarian emergency, collaborating effectively with the private sector. The regional emergency coordination structure generally worked well, particularly in supporting the operation in Syria. WFP coordinated effectively with other United Nations agencies and structures.

Lozi (2013) investigates the effects of both Syrian and Iraqi refugees on Jordan. Using foreign direct investment and food pricing, the author concludes that the presence of refugees increased the food prices in Jordan. Moreover, the study indicates that refugees in Jordan have had an impact on the national budget (leading to an expansionary budget in 2012) due to the considerable increase in school enrollment, use of public hospitals for health care, and the upsurge in consumption of government-subsidized fuel and water. The study concludes that the effects of refugees were overstated in terms of positive and negative effects, indicating that refugees could not be held accountable for most of the economic challenges in Jordan.

\section{Comment on previous studies}

It is noted through the review of previous studies that most of these literature are not in-depth in the main study topic related to the extent of the contribution of the World Food Program to improving the conditions of Syrian refugees in Jordan, most studies talk about the numbers of refugees and their living conditions and the economic and educational reality and other basic needs that obligate it, and to the extent The researcher has learned that there are few studies that measure the impact of humanitarian aid on Syrian refugees in Jordan in terms of their empowerment and integration into society.

\section{Study methodology}

The study followed the descriptive analytical method, as it is suitable for such type of studies.

\section{Study community}

The study population consisted of Syrian refugees in Jordan.

\section{The study sample}

The sample of the study was chosen by the stratified random method from the Syrian refugees inside Zaatari camp and outside the camp in the Jordanian city of Mafraq, which consists of (220) refugees as shown in Table No. (1).

Table (1)

Study sample members

\begin{tabular}{|c|c|c|}
\hline Variables & & No \\
\hline Gender & Male & 141 \\
\hline & Female & 79 \\
\hline & Total & 220 \\
\hline Location & Zaatari refugee camp & 115 \\
\hline & Outside the camp & 105 \\
\hline & Total & 220 \\
\hline
\end{tabular}

\section{The study's Instrument}

To meet study's goals, the researcher developed the study's instrument based on the relevant literature and pervious studies. The role of world food programme in improving the conditions of the Syrian refugees in Jordan. A questionnaire was developed consisting of 12 article paragraphs, in addition to the demographic variables (gender, location).

The degree of approval of the study sample was estimated on the tool's paragraphs according to the Likert 
five-point scale, according to the following distribution: (To a very large degree, to a large degree, to a medium degree, to a degree, to a very small degree), and these categories represent the following points, respectively: (1, $2,3,4,5)$.

\section{Reliability Instrument}

The concept of instrument validity indicates the degree to which the study instrument in use actually measures its measurement revenue, and honesty was measured through the use of a number of experts from professors to judge the questionnaire.

\section{validity Instrument}

To verify the stability of the questionnaire, the coefficients of Alpha-Cronbach were calculated, and it reached ((0.911) which is suitable for conducting the study

\section{Variables Instrument}

The study included the following variables:

The independent variable: demographic variables (gender, location - Zaatari camp, outside the camp)

Dependent variable: The role of world food programme in improving the conditions of the Syrian refugees in Jordan.

\section{Statistical processing methods}

Data collected by study questionnaire were valid and reliable to carry out the statistical analysis. questionnaires collected were used for analysis using Statistical Package for Social Sciences (SPSS) software.

\section{The following was used:}

- Frequencies and percentages to describe the characteristics of the study sample.

- Arithmetic mean and standard deviations to know the responses of the sample members on each of the questionnaire paragraphs.

- Cronbach's Alpha lab to verify resolution.

- Multiple variance analysis.

The following ranking was used to indicate the mean responses of the sample individuals:

1. Low level from 1.00 to 2.33

2. Intermediate level from 2.34 to 3.67

3. The high level from 3.68 to 5.00

\section{The Study's Results and Discussion}

Results and discussion related to the first question:

Q1: Is world food programme improving the conditions of the Syrian refugees in Jordan from refugees point view?

To answer this question, the mean and standard deviations were extracted for the scale phrases of the contribution of the World Food Program to improving the conditions (living, health) of the Syrian refugees in Jordan.

Table (2)

Arithmetic mean, standard deviations, grade and grade for study sample estimates of the role of the World Food Program in improving living conditions

\begin{tabular}{|c|c|c|c|c|}
\hline No & Statements & S.D & M & Degree \\
\hline 3 & The World Food Program improves my living conditions & .620 & 3.67 & Moderate \\
\hline 2 & $\begin{array}{l}\text { The higher food program contributes to providing part of the family's daily } \\
\text { expenses }\end{array}$ & .435 & 3.65 & Moderate \\
\hline 6 & The World Food Program meets basic food needs & .456 & 3.59 & Moderate \\
\hline 5 & The World Food Program contributes to providing food for children & .731 & 3.57 & Moderate \\
\hline 1 & The World Food Program provides food continuously & .597 & 3.51 & Moderate \\
\hline 4 & The World Food Program increases the chances of a decent family life & .652 & 3.50 & Moderate \\
\hline \multicolumn{2}{|r|}{ Total } & .671 & 3.63 & Moderate \\
\hline
\end{tabular}

Table (2) shows that the level of improvement in the living conditions of Syrian refugees in Jordan as a result of the World Food Program came with a medium degree, where the total arithmetic mean (3.63) and standard deviation (0.671) and an average degree.

And the phrase No. (3) Which states "The World Food Program improves my living conditions" got the 
first rank with an average mean of (3.67) and a standard deviation of (.620) with an average degree, while the phrase No. (4) which states "The World Food Program increases the chances of a decent family life "on the last rank with an arithmetic average of (3.50) and a standard deviation of (.652) and an intermediate degree.

These results indicate that the World Food Program contributes to improving the living conditions of the Syrian refugees in a moderate degree, as the program plays an important role in alleviating the financial burdens on the refugees by providing food free of charge through purchase vouchers.

Table (3)

Arithmetic mean, standard deviations, grade and grade for study sample estimates of the role of the World Food Program in improving health conditions

\begin{tabular}{|c|l|c|c|c|}
\hline No & \multicolumn{1}{|c|}{ Statements } & S.D & M & Degree \\
\hline 9 & $\begin{array}{l}\text { The World Food Program contributes to improving the family's health } \\
\text { conditions }\end{array}$ & .610 & 3.64 & Moderate \\
\hline 7 & The World Food Program provides healthy food & .377 & 3.63 & Moderate \\
\hline 10 & The World Food Program provides diverse food to refugees & .394 & 3.60 & Moderate \\
\hline 8 & The World Food Program works integrated with health institutions & .482 & 3.55 & Moderate \\
\hline 12 & The World Food Program is important for Syrian refugees & .771 & 3.53 & Moderate \\
\hline 11 & The World Food Program contributes to improving children's health & .721 & 3.09 & Moderate \\
\hline \multicolumn{2}{|c|}{ Total } & .501 & 3.59 & Moderate \\
\hline
\end{tabular}

Table (2) shows that the level of improvement of the health conditions of Syrian refugees in Jordan as a result of the World Food Program came with a medium degree, where the total arithmetic mean (3.59) and a standard deviation (0.671) and an average degree.

The phrase No. (9) which states "The World Food Program contributes to improving the family's health conditions s" got the first rank with an average mean of (3.64) and a standard deviation of (.610) at a moderate degree, while the term No. (11) which It states "The World Food The World Food Program contributes to improving children's health" with a mean score of (3.09) and a standard deviation of (.721) with a moderate degree.

These results indicate that improving the health conditions of Syrian refugees is inseparable from ensuring healthy and safe food and the provision of basic materials provided by the World Food Program to Syrian refugees inside and outside the refugee camps.

Results and discussion related to the second question: Is there any statistically significant difference in improving the conditions of the Syrian refugees due to world food programme which can be attributed to (gender, location)?

To answer this question, the mean and standard deviations of the Syrian refugee estimates of the extent of the World Food Program contribution to improving conditions for refugees in Jordan were extracted according to (Gender, Location) variables.

Table (4)

Arithmetic mean and standard deviations of Syrian refugee estimates of the extent to which the World Food Program has contributed to improving conditions for refugees in Jordan, according to (Gender, Location) variables.

\begin{tabular}{|c|r|c|c|c|}
\hline Variables & Category & No & S.D & M \\
\hline \multirow{2}{*}{ Gender } & Male & 141 & 0.72 & 3.51 \\
\cline { 2 - 4 } & Female & 79 & 0.33 & 3.49 \\
\hline \multirow{2}{*}{ Location } & Inside The Camp & 151 & 0.44 & 3.65 \\
\cline { 2 - 4 } & Outside The Camp & 99 & 0.91 & 3.41 \\
\hline
\end{tabular}

Table 4 shows that there are apparent differences between the arithmetic mean of the Syrian refugee estimates of the extent of the contribution of the World Food Program to improving conditions for refugees in Jordan, according to (Gender, Location) variables. To determine whether these differences were statistically significant at the level $(\alpha=0.05)$, multiple variance analysis was applied, and the results of variance analysis came as shown in Table (5).

Table (5)

Results of the multiple contrast analysis test to see the significance of the differences

\begin{tabular}{|l|c|c|c|c|c|}
\hline \multicolumn{1}{|c|}{ Source } & Sum of Squares & Df & Mean Square & F & Sig. \\
\hline Gender & .255 & 1 & 0.255 & 0.741 & 0.119 \\
\hline Location & .033 & 1 & 0.033 & 0.187 & 0.003 \\
\hline Error & 83.103 & 216 & 0.316 & & \\
\hline Total & 1612.420 & 220 & & & \\
\hline
\end{tabular}

* Statistical significance at the significance level $(=0.05=\alpha)$

The results of Table (4) show that there are no statistically significant differences in the estimates of Syrian 
refugees by the extent of the contribution of the World Food Program to improving conditions for refugees in Jordan, according to the gender variable, as the level of significance $((0.119)$ according to the gender variable, while the results showed the presence of significant differences A statistic in the Syrian refugee estimates of the extent of the contribution of the World Food Program to improving conditions for refugees in Jordan according to the location variable and the level of significance reached $(0.003)$. The differences came in favor of the refugees inside the camp.

This result indicates the importance of the World Food Program for refugees inside the camp more than refugees outside the community, especially that refugees outside the community are involved in the local community and get appropriate job opportunities that help them secure their basic needs better than refugees inside the camp.

\section{Recommendations}

Based on the findings of the study, the study recommends the following

- Increase the allocations provided by the governments of the world countries to support the World Food Program to better provide its services.

- Maintaining the continuity of the work of the World Food Program in Jordan due to its importance for the Syrian refugees.

\section{References}

1. Al-Hammoud, Waddah (2015) Status of Refugees in the Hashemite Queen of Jordan, Scientific Forum: Asylum and Dimensions, Juma Nayef for Security Sciences, Riyadh.

2. Alshoubaki, W., \& Harris, M. (2018).The impact of Syrian refugees on Jordan: A framework for analysis. Journal of International Studies, 11(2), 154-179. doi:10.14254/2071-8330.2018/11-2/11

3. Burhan, Ordinance (1982) The Right to Political Asylum A study in the theory of asylum right in international law, i 1, Arab Renaissance House, Cairo.

4. Jordan Annual Country Report 2018 Country Strategic Plan 2018 - 2019 ACR Reading Guidance

5. Drummond, J., Khoury, R., Sarah B., Nicholas C., Lilianne F., Rand M., Steven A.(2014) An Evaluation of WFP's Regional Response to the Syrian Crisis, 2011-2014 Evaluation Report. WFP Office of Evaluation Report number: OEV/2014/19.

6. Husain, A., Bauer, j., Sandström, S. (2014) Economic Impact Study: Direct And Indirect Impact Of The Wfp Food Voucher Programme In Jordan: https://www.calpnetwork.org/wpcontent/uploads/2020/01/economic-impact-study-wfp-jordan.pdf

7. Schillings, T. (2018) The macro-economic impacts of Syrian refugee aid. Forced Migration Review Refugee Studies Centre. University of Oxford.

8. Connable , B. (2015) From Negative to Positive Stability How the Syrian Refugee Crisis Can Improve Jordan's Outlook. Library of Congress Cataloging-in-Publication Data is available for this publication. ISBN: 978-0-8330-9087-4 RAND Corporation, Santa Monica, Calif.

9. Fakih, A., \& Ibrahim, M. (2016) The Impact of Syrian Refugees on the Labor Market in Neighboring Countries: Empirical Evidence from Jordan. IZA Discussion Paper No. 9667.

10. Lozi, B. (2013) The effect of refugees on host country economy, evidence from Jordan. Interdisciplinary Journal of Contemporary Research in Business 5 (3): 114-126.

11. World Food Programme (WFP): htpp//www.wfp.org. 